\title{
ИССЛЕДОВАНИЕ СООТВЕТСТВИЯ ОТДЕЛЬНЫХ ДЕЙСТВУЮЩИХ НОРМАТИВНО-ОРГАНИЗАЦИОННЫХ ТРЕБОВАНИЙ В ОБЛАСТИ ОХРАНЫ ТРУДА УСЛОВИЯМ ПАНДЕМИИ COVID-19
}

\author{
Павел Васильевич Мучин \\ Сибирский государственный университет геосистем и технологий, 630108, Россия, \\ г. Новосибирск, ул. Плахотного, 10, доцент кафедры техносферной безопасности, тел. (383)344-42-00, \\ e-mail: p.v.muchin@ssga.ru
}

\section{Максим Павлович Мучин}

Сибирский государственный университет телекоммуникаций и информатики, 630100, Россия, г. Новосибирск, ул. Кирова, 86, обучающийся, тел. (906)195-12-01, e-mail: maxim4521@yandex.ru

Выполнен анализ отдельных нормативных правовых актов в области охраны труда, определяющих общие нормативно-организационные требования по обеспечению безопасности и сохранения здоровья персонала на уровне предприятия. Представлены рекомендации по внесению дополнений в отдельные действующие нормативные правовые акты в области охраны труда, а так же рекомендации по разработке локальных нормативных актов, регулирующих вопросы охраны труда на предприятиях в условиях пандемии COVID-19.

Ключевые слова: охрана труда, нормативные правовые акты, локальные нормативные акты, пандемия COVID-19

\section{STUDY OF COMPLIANCE OF CERTAIN EXISTING REGULATORY AND ORGANIZA- TIONAL REQUIREMENTS IN THE FIELD OF LABOR PROTECTION WITH THE CONDI- TIONS OF THE COVID-19 PANDEMIC}

\section{Pavel V. Muchin}

Siberian State University of Geosystems and Technologies, 10, Plakhotnogo St., Novosibirsk, 630108, Russia, Associate Professor, Department of Technosphere Safety, phone: (383)343-42-00, e-mail: p.v.muchin@ssga.ru

\section{Maxim P. Muchin}

Siberian State University of Telecommunications and Informatics, 86, Kirova St., Novosibirsk, 630100, Russia, Student, phone: (906)195-12-01, e-mail: maxim4521@yandex.ru

The analysis of separate regulatory legal acts in the field of labor protection, which define General regulatory and organizational requirements for ensuring the safety and health of personnel at the enterprise level, is performed. Recommendations for making additions to certain existing regulatory legal acts in the field of labor protection, as well as recommendations for the development of local regulations governing labor protection at enterprises in the context of the COVID-19 pandemic are presented.

Keywords: labor protection, regulations, local regulations, COVID-19 pandemic

В настоящей работе не предполагается давать специфическую медицинскую и статистическую информацию, связанную с короновирусом COVID-19. Наша задача заключается в исследовании соответствия отдельных нормативных 
правовых актов в области охраны труда и сохранения здоровья работников в условиях введенных ограничений в связи с объявленной пандемией COVID-19.

В конце января этого года Всемирная организация здравоохранения (BO3) сообщила о чрезвычайной ситуации, а в марте объявила о пандемии. Как известно, пандемия (греч. $\pi \alpha v \delta \eta \mu i ́ \alpha$ «весь народ») - необычайно сильная эпидемия, распространившаяся на территории стран, континентов; высшая степень развития эпидемического процесса.

В Российской Федерации положение с инфекцией короновируса очень напряженное. Большинство специалистов считает, что эпидемия не закончится и в 2021 году, а заболеваемость будет зависеть от соблюдения ограничительных мер и пойдет на спад только после массовой вакцинации.

На наш взгляд, учитывая недостоверность приводимых статистических данных, наше, зачастую пренебрежительное, отношение к ограничительным мерам, чрезвычайно низкое в настоящее время доверие населения к предлагаемым вакцинам и лекарствам от короновируса, можно сделать вывод - возникшие проблемы это надолго. Соответственно целесообразно проанализировать отдельные действующие нормативные правовые акты и, соответственно, локальные нормативные документы, разрабатываемые на уровне предприятия (организации, учреждения) с целью уточнения их соответствия возникшим новым условиям трудовой деятельности.

Анализ показывает, что уже существуют и постоянно добавляются различные указания, постановления, рекомендации и другие нормативно-организационные документы, направленные на реализацию различными органами власти, руководителями организаций и гражданами мероприятий и действий в условиях пандемии. Содержание этих документов, как правило, носит общий характер и не предполагает получение ответов в отдельных конкретных ситуациях, в том числе и в области охраны труда.

Ниже предлагаются результаты нашей оценки по отдельным документам, регулирующим вопросы охраны труда.

Как известно, трудоохранное законодательство возлагает на работодателя множество обязанностей, направленных на создание безопасных условий труда, сохранение жизни и здоровья работников. Создание системы управления охраной труда (СУОТ) на уровне организации, включает в себя разработку ряда локальных нормативных актов и мероприятий в области охраны труда. Например, уже на стадии приема на работу, работодатель обеспечивает:

- прохождение обязательного предварительного медицинского осмотра;

- для отдельных работников психиатрическое освидетельствование;

- проведение вводного инструктажа по охране труда и инструктажа по охране труда на рабочем месте;

- в отдельных случаях стажировку работников.

Целесообразно, чтобы уже при прохождении медицинского осмотра учитывались требования профилактики короновирусной инфекции. 
Так как инструктажи по охране труда проводятся по разработанным и утвержденным в организации программам, то необходимо эти программы пересмотреть с учетом существующих требований по профилактике короновирусной инфекции. При этом обязательно учитывается вид выполняемой работы и условия трудовой деятельности, то есть по существу необходимо учитывать результаты специальной оценки условий труда (СОУТ) и оценки производственного контроля за соблюдением санитарных правил и выполнением санитарно-противоэпидемических (профилактических) мероприятий.

В дальнейшем работник проходит обязательное обучение и аттестацию по охране труда. Обучение проводиться по утвержденным в организации программам. Аттестация работников по охране труда выполняется разными методами с включением контрольных вопросов. Очевидно, что и на этом этапе необходимо учитывать рекомендованные требования по профилактике короновирусной инфекции.

Важная задача работодателя обеспечить работников инструкциями по охране труда. В настоящее время инструкции по охране труда разрабатываются с учетом «Методических рекомендаций по разработке государственных нормативных требований охраны труда», утвержденных постановлением Минтруда России в 2002 году.

В инструкциях по охране труда для работников разрабатываются следующие разделы:

1. Общие требования охраны труда;

2. Требования охраны труда перед началом работы;

3. Требования охраны труда во время работы;

4. Требования охраны труда в аварийных ситуациях;

5. Требования охраны труда по окончанию работы.

На наш взгляд рекомендации по профилактике короновирусной инфекции могут быть отражены в каждом из разделов инструкции. Допустимо введение в инструкцию дополнительного раздела с рекомендациями по профилактике короновирусной инфекции.

Вопросы профилактики короновирусной инфекции необходимо так же учитывать при организации целевого инструктажа по охране труда. По нормативным документам целевой инструктаж по охране труда проводят перед выполнением:

- работ с повышенной опасностью, на которые в соответствии с нормативными документами требуется оформление наряда-допуска, разрешения или других специальных документов;

- разовых работ, в том числе не связанных с прямыми обязанностями по специальности, профессии;

- иных работ с повышенным риском опасного воздействия на организм работающего;

- работ при ликвидации последствий аварий, стихийных бедствий и т.п. 
Очевидно, что целевой инструктаж может быть на различных объектах, в том числе и на территории другой организации, что обуславливает повышенные требования к обеспечению безопасности и сохранению здоровья работников, в том числе в условиях возможного заражения короновирусной инфекцией.

Важнейшая задача работодателя обеспечить работников индивидуальными средствами защиты (СИЗ). В этом случае применяются документы, разработанные и утвержденные еще задолго до объявления пандемии COVID-19. Учитывая, что основная обязанность работодателя, это обеспечить безопасность и сохранение здоровья работников, становиться очевидным, что и при обеспечении работников СИЗ, следует дополнительно учитывать основные рекомендации по профилактике короновирусной инфекции.

В настоящее работе можно было бы продолжить анализ и других нормативных правовых актов в области охраны труда. Соответственно, учитывая, что пандемия COVID-19 пришла к нам надолго, мы практически для всех документов нашли бы возможность рекомендовать пересмотр и внесение каких либо изменений и дополнений. Например, работодатель обязан организовать обучение работников по оказанию первой помощи пострадавшим. Существующие документы по организации такого обучения естественно не учитывают настоящих официальных рекомендаций по профилактике короновирусной инфекции. Требуется проанализировать нормативные документы по специальной оценке условий труда, оценке профессионального риска работников и многое другое.

В заключение отметим следующее:

1. Федеральные органы исполнительной власти, очевидно, не начали работу по анализу действующих нормативных правовых актов в области охраны труда на соответствие требованиям профилактики короновирусной инфекции;

2. Учитывая обязанность работодателя обеспечить безопасность и сохранение здоровья работников, рекомендуется всем организациям провести работу по пересмотру собственных локальных нормативных актов по охране труда даже при отсутствии соответствующих нормативных правовых актов Федеральных органов исполнительной власти;

3. В качестве примера отметим, что отдел охраны труда Центра безопасности труда СГУГиТ начал пересмотр инструкций по охране труда с учетом рекомендаций по профилактике короновирусной инфекции. Продолжается работа по пересмотру программ инструктажей и обучения по охране труда.

\section{БИБЛИОГРАФИЧЕСКИЙ СПИСОК}

1. Трудовой кодекс Российской Федерации от 30.12.2001 №197-Ф3 [Электронный ресурс] - Режим доступа: http://www.consultant.ru/document/cons_doc_LAW_34683/.

2. Порядок обучения по охране труда и проверки знаний требований охраны труда работников организаций. Утверждён совместным постановлением Минтруда России и Минобразования России от 13.01.2003 г. № 1/29 (с изменениями и дополнениями от 30.11.2016 г.) [Электронный ресурс] - Режим доступа: http://ivo.garant.ru/\#/document/185522/.

3. ГОСТ 12.0.004-2015 ССБТ. Организация обучения по безопасности труда. Общие положения [Электронный ресурс] - Режим доступа: https://ohranatruda.ru/ot_biblio/standart/208368/. 
4. Межотраслевые правила обеспечения работников специальной одеждой, специальной обувью и другими средствами индивидуальной защиты. Утверждены приказом Минздравсоцразвития России от 1.06.2009 г. № 290н (с изменениями и дополнениями от 12.01.2015 г.) [Электронный ресурс] - Режим доступа: http://ivo.garant.ru/\#/document/12169526/.

5. «Перечень состояний, при которых оказывается первая помощь» и «Перечень мероприятий по оказанию первой помощи». Утверждены приказом Минздравсоцразвития России от 4.05.2012 г. № 477н (с изменениями и дополнениями от 7.11.2012 г.) [Электронный ресурс] Режим доступа: http://ivo.garant.ru/\#/document/70178292/.

6. Методика проведения специальной оценки условий труда. Утверждена приказом Минтруда России от 24.01.2014 г. № 33н. (с изменениями от 27.04.2020 г.) [Электронный ресурс] - Режим доступа: http://ivo.garant.ru/\#/document/70583958/.

7. Типовое положение о системе управления охраной труда. Утверждено приказом Минтруда России от 19.08.2016 г. № 438н [Электронный ресурс] - Режим доступа: http://ivo.garant.ru/\#/document/71513730/.

8. Типовой перечень ежегодно реализуемых работодателем мероприятий по улучшению условий и охраны труда и снижению уровней профессиональных рисков. Утвержден приказом Минздравсоцразвития России от 1.03.2012 г. № 181н (с изменениями от 16.06.2014 г.) [Электронный ресурс] - Режим доступа: http://ivo.garant.ru/\#/document/70150478/.

9. Руководство по оценке профессионального риска для здоровья работников. Организационно-методические основы, принципы и критерии оценки [Электронный ресурс] Руководство Р 2.2.1766-03. Утверждено Главным государственным санитарным врачом Российской Федерации 24.06.2003 г. [Электронный ресурс]. - Режим доступа: https://ohranatruda.ru/ot_biblio/norma/246225/. 